\title{
Utilization of Agricultural Wastes in the Manufacture of Composite Boards
}

\author{
P. M. MACATANGAY' ${ }^{1}$ E. C. MAGUNDAYAO ${ }^{1}$ AND C. A. M. ROSALES $^{1}$
}

\begin{abstract}
Development of useful composite materials out of agricultural waste has become a desirable option in recycling. This led to the production of composite boards being used in the construction industry. In this paper, three types of available agricultural wastes in the province of Batangas - peanut shells, corn husks and banana sheath - were independently utilized in the production of composite boards. The raw materials were either air or sun dried, then crushed (for peanut shells) and extracted (for banana sheath and corn husks) before mixing with the binder. Urea formaldehyde (UF) was used as binder for peanut shells and banana sheaths while cleaned used plastic bags were chopped and mixed with corn husks before subjecting to hot compress machine. For each mat, the following proportions were used:1000 gm banana fibres, $500 \mathrm{gm}$ of UF mixed with $250 \mathrm{gm}$ of water; $720 \mathrm{gm}$ of crushed peanut shells, 133 gm UF with $12 \%$ resin content; $40 \%$ corn husks, $60 \%$ plastic strips by weight. The physical and mechanical characteristics like modulus of rupture (MOR), internal bond, face screw head test (FSHT) or Nail Head Pull through (NHPT), water absorption and thickness swelling were determined for each board and the results were compared to the values set by the Philippine National Standards (PNS). Based on statistical results, the corn husk-plastic composite boards conformed to all parameters in the PNS; the density, thickness swelling, IBS, and NHPT/ FSHT of peanut shell-resin composite boards conformed to the PNS; and the thickness swelling, density, MOR and NHPT/FSHT of the banana sheath-UF composite boards conformed to the PNS.
\end{abstract}

Key words: agricultural wastes; composite boards; peanut shells; corn husks; banana sheath; urea formaldehyde

Growing concern for waste minimization led the construction industry to consider the use of agricultural waste in the production of building materials. The Philippines, being an agricultural country produces considerable amount of agricultural waste. As of 1999, generation of 40 million metric tons of agricultural wastes was documented by the Department of Energy (Baconguis 2008). This includes wastes from sugarcane, coconut, corn, rice and logs. If such waste is not be utilized, it will cover a large area of landfill.
Thus, the idea of using agricultural wastes as a renewable resource became an optimistic option to minimize this waste. Different types of agricultural waste are viable for a wide variety of products including paper, textiles, other fibrebased materials and wood-based panels such as fibreboards and particleboards (Magundayao et al. 2006; Macatangay 2010).

Composite panels made from agricultural materials are in the same product category as wood-based composite panels and include

\footnotetext{
${ }^{1}$ Faculty of the Department of Civil and Environmental and Sanitary Engineering, Batangas State University, Governor Pablo Borbon Main Campus II, Batangas City, Philippines 4200

*Corresponding author (e-mail: pauline_mac_2000@yahoo.com; c.magi@yahoo.com; cristinaamor@yahoo.com)
} 
low-density insulating board, medium-density fibreboard, hardboard, and particleboard. More so, composite panel binders may be synthetic thermosetting resins or modified naturallyoccurring resins like tannin or lignin, starches, thermoplastics, and inorganics (Rowell 1996).

Strength properties as well as other characteristics suited for their intended uses or application for various construction materials are prescribed by the Philippine National Standard (PNS). These are approved by the Bureau of Product Standards. PNS requirements for particle boards are shown in Table 1 .

In Batangas State University, the Department of Civil Engineering conducted independent studies on the utilization of agricultural wastes available in the province. These studies focused on the use of corn husks, peanut shells and banana sheath as main components of composite boards.

\section{Corn Husk}

As of 2008, approximately 2,490,000 hectares of land in the Philippines were utilized for corn production area (Philippines Agriculture 2003-2009). Farmers typically leave husks and stalks behind in the fields as waste materials. According to Ohio State University, approximately 50 percent of the weight of the total corn plant is residue, consisting of stalk, leaf, cob and husk. In fact, $10 \%$ of dry matter residue came from corn husk (Myers 2009).

Corn husk is $80 \%-87 \%$ cellulose material. Its tensile properties show that corn fibre has the unique advantage of moderate strength but with higher toughness, low modulus and higher elongation (Reddya \& Yang 2005) which makes it comparable to existing fibres used for the production of fibreboard.

\section{Peanuts Shell}

Peanuts are very popular in the Philippines but not much attention is given to this crop for research and development. Almost 35,000 metric tons are harvested each year (Palomar 1998). The shells, which are biodegradable and absorbent, can be utilized as animal food filler, absorbents, or carriers for pesticides or fertilizers, although they are often simply landfilled (Bieak \& George 2003; "Hulls" AgTech 2002).

Dried, ground peanut hulls were found to contain $34.56 \%$ lignin, $39.42 \%$ cellulose, $73.98 \%$ acid detergent fibre and $86.16 \%$ neutral detergent fibre (Childs \& Abajian 2006). This characteristic is comparable to wood which is composed of fibres of cellulose $(40 \%-50 \%)$ and hemicellulose $(15 \%-25 \%)$ held together by lignin $(15 \%-30 \%), 60 \%$ crude fibre, $7 \%$ protein and $3 \%$ ash (University of Minnesota Extension N.D.).

\section{Banana Sheath}

As of 2004, 5.9 million farm households were depending on banana as their source of income. Banana is still the leading fruit crop in terms of area, volume and value of production. The national average yield is 9.4 tons per hectare while corporate plantations produce 40 tons

Table 1. Particleboard properties set by the Philippine National Standards (1987).

\begin{tabular}{c|cccccc}
\hline \multirow{2}{*}{ Type } & $\begin{array}{c}\text { MOR } \\
(\text { Min- }\end{array}$ & $\begin{array}{c}\text { IB } \\
(\text { Min- }\end{array}$ & \multicolumn{2}{c}{$\begin{array}{c}\text { FSHT/Density } \\
\text { NHPT }\end{array}$} & $\begin{array}{c}\text { WA } \\
(\text { Max-\% })\end{array}$ & $\begin{array}{c}\text { TS } \\
(\text { Max-\%) }\end{array}$ \\
& $\left(\mathrm{kg} / \mathrm{cm}^{2}\right)$ & $\left(\mathrm{kg} / \mathrm{cm}^{2}\right)$ & $(\mathrm{kg})$ & $(\mathrm{g} / \mathrm{cc})$ & & \\
\hline 200 & 180 & 5 & $30-50$ & $0.4-0.8$ & 30 & 20 \\
150 & 140 & 3 & $30-50$ & $0.4-0.8$ & 30 & 20 \\
100 & 80 & 2 & $30-50$ & $0.4-0.8$ & 30 & 20 \\
\hline
\end{tabular}


per hectare. It is a widely grown fruit in the country, planted as a component of farming system or as a main crop in large plantations in Mindanao. It is an important source of income for small farmers who constitute $80 \%$ of the banana growers (Rivera 2004).

Banana has different plant parts that could be good sources of various industrial products, aside from its fruit, its main product. The plant's psuedostem or trunk contains fibre that can be manufactured into rope, sack and mat. Pablo (1975) cited in his study that banana stalk is a potential source of material for the production of boards.

\section{OBJECTIVES}

This study aims to present the characteristics of composite boards produced using agricultural waste. Specifically, the study aims to:

- Present the individual characteristics of composite boards in terms of their (a) physical characteristics, and (b) mechanical properties

- Compare the properties of the agricultural waste composite boards with those prescribed by the Philippine National Standard (PNS).

\section{MATERIALS AND METHODS}

Each of the materials was collected from the locality: corn husks were gathered from Alitagtag, Batangas; peanut shells from peanut butter manufacturing industry in Batangas City; banana stalks were harvested from a small scale banana plantation in Batangas. These materials were sorted cleaned and dried.

Different binding agents were used in the composite boards. Corn husk fibreboard used waste plastics as binding agent while for the peanut shell particle board and banana sheath fibreboard, urea formaldehyde (UF) was used.
Banana fibres were extracted from the trunks which were soaked in water for a week, by pounding using a wooden mallet. The fibres were air dried for one full day. A set of comblike row of pins were used to separate the fibres. For five minutes the fibres were oven dried at $100^{\circ} \mathrm{C}$ then cut into $5 \mathrm{~cm}$ long pieces before mixing with UF and shaped into $300 \mathrm{~mm}$ by $300 \mathrm{~mm}$ mat. For each mat $1000 \mathrm{gm}$ of fibres were used with $500 \mathrm{gm}$ of powder UF mixed with 250 gm of water.

Peanut shells were sun dried until they became brittle and crushed using an electric food processor. Mats were formed from a mixture of 720 grams of crushed peanut shells and 133 grams of UF with $12 \%$ resin content.

Corn husks were sun dried for three days at approximately $30^{\circ} \mathrm{C}-35^{\circ} \mathrm{C}$ temperature and then cut into about $5 \mathrm{~mm}$ wide and $40 \mathrm{~mm}$ long pieces and mixed with dry plastic strips of the same size. A $40 \%-60 \%$ proportion by weight was considered in forming the $30 \mathrm{~cm} \times 30 \mathrm{~cm}$ $\times 1.2 \mathrm{~cm}$ boards.

The moulded mats were separately placed in the Type VH2-749 Kitagawa hot press machine for about 20 minutes at a temperature of $150^{\circ} \mathrm{C}$ to achieve a thickness of $12 \mathrm{~mm}$. Before testing, the boards were set aside for approximately three days then cut into $5 \mathrm{~cm} \times 5 \mathrm{~cm}$ specimen sizes. A 5-ton Shimadzu Type RH10 Universal Testing Machine was used to test the modulus of rupture, internal bond strength and nail head pull through of the specimens.

Figure 5 shows the process of production of the composite boards. This process was recommended and implemented by Forest Products Research and Development Institute (FPRDI), an agency under the Department of Science and Technology (DOST) in Los 


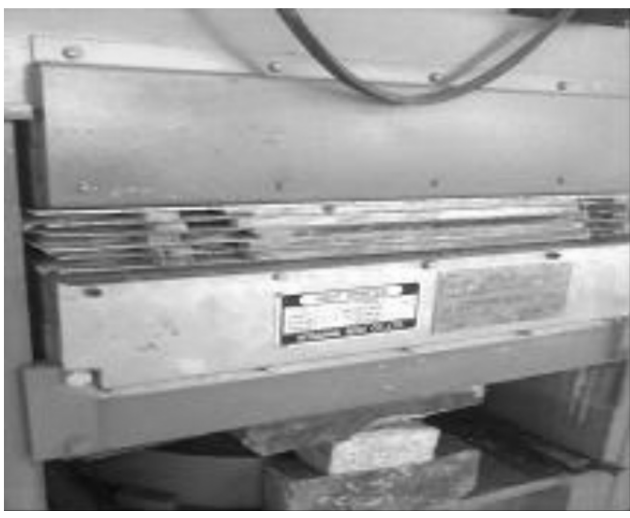

Figure 1. The hot compress machine used to form the boards.

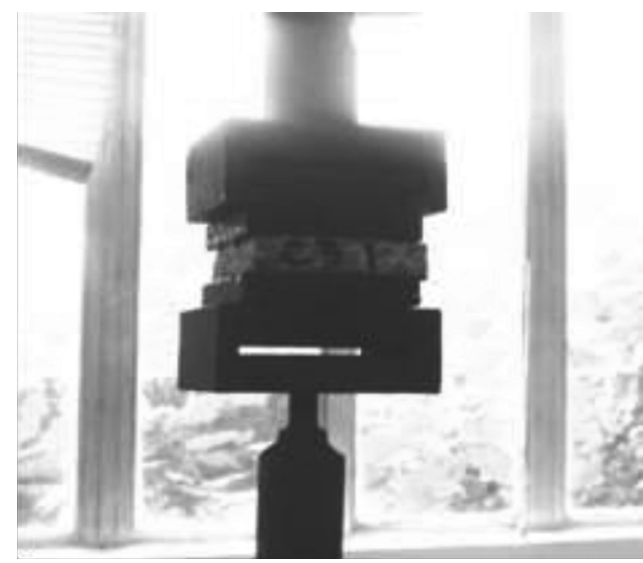

Figure 2. Test for internal bond strength.

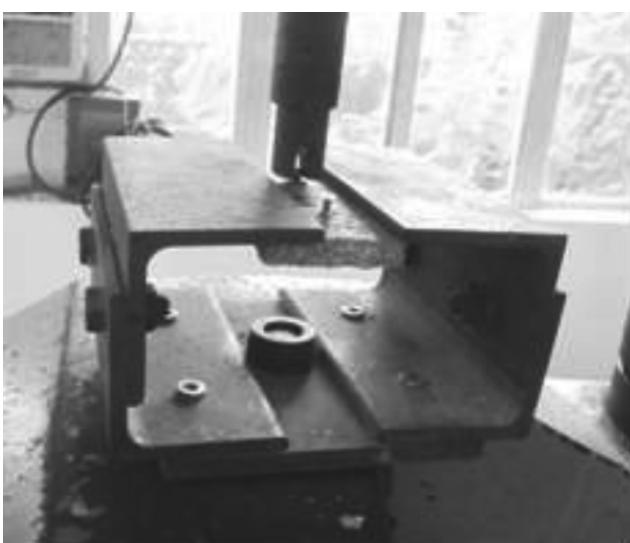

Figure 3. Test for modulus of rupture.

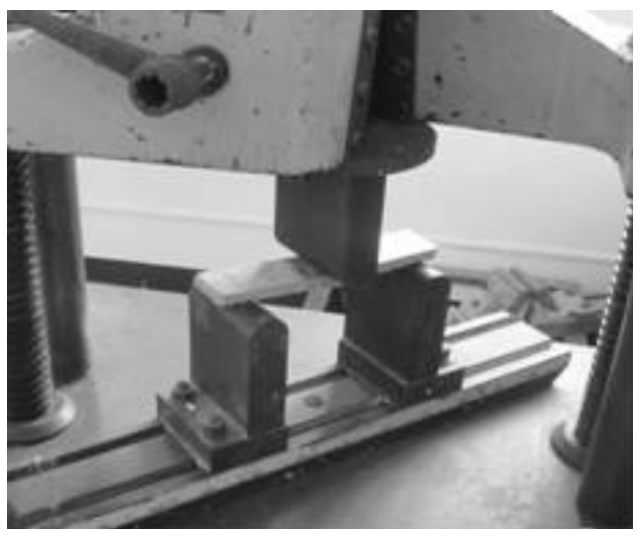

Figure 4. Test for screw holding capacity.

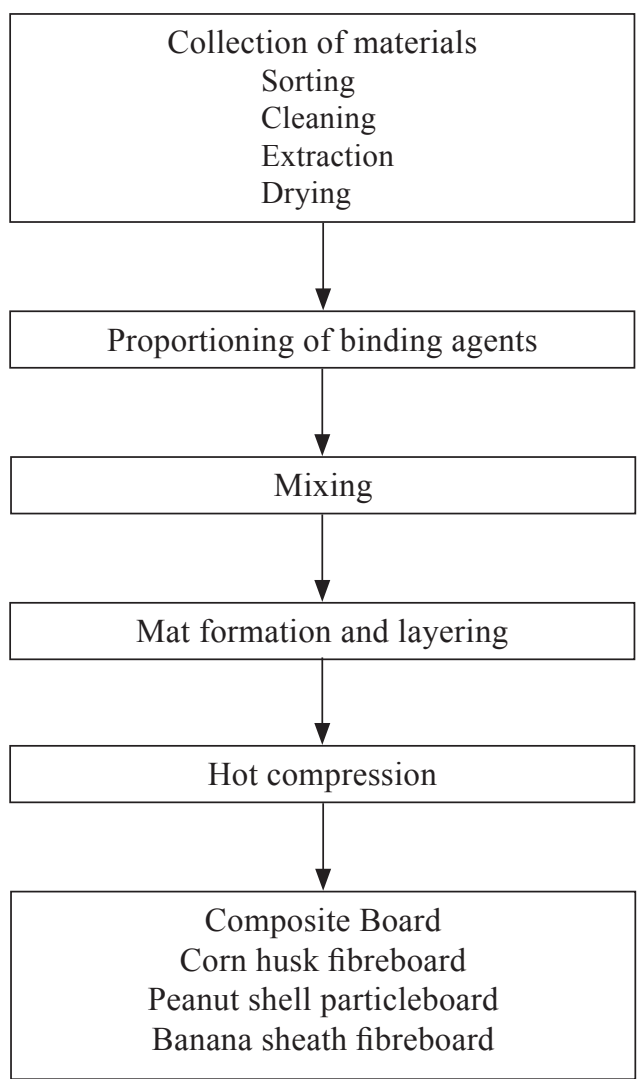

Figure 5. Composite boards production process. 
Baños, Laguna, Philippines for the production of composite boards. This is also where the production and test procedures were done for the three boards.

Each board utilized different proportions of binding agents. Table 2 shows the proportioning of materials and the binding agent used.

\section{Property Testing and Analysis}

To determine the different characteristics of the specimens produced, the following tests and analyses were conducted. Test procedures were patterned from the Philippine National Standards for Composite Boards (PNS 26). Tests performed are shown below.

Physical properties. The process determines the length, width, thickness, mass and density of the boards. The physical properties were determined using a caliper and an analytical balance.

Modulus of rupture (MOR). The MOR test was performed in order to determine the strength against bending using the Universal Testing Machine (UTM). The specimen's dimensions were taken and then, force was applied using the UTM. The reading from the UTM determined the load capacity of the board.
The MOR, or bending strength, was then obtained using the formula:

$\operatorname{MOR}\left(\mathrm{kg} / \mathrm{cm}^{2}\right)=\frac{3 P \times S}{2 W \times T \times H^{2}}$

where,

$P=$ Ultimate load (kg); $S=$ Length or span (cm); $W=$ Width (cm); $T=$ Thickness (cm).

Internal bond strength (IB). Internal Bond is a mechanical property of materials referring to the tensile strength perpendicular to the plane of the board. IB measured the quality of the particle-to-particle bonding.

The IB Test was computed using the formula:

$$
\text { IB }\left(\mathrm{kg} / \mathrm{cm}^{2}\right)=\frac{P}{A}
$$

where,

$P=\operatorname{Load}(\mathrm{kg}) ; A=$ Area of test piece; = Length $\times$ Width.

Face screw head test (FSHT) / Nail head pull through (NPHT). The FSHT or NHPT determines the capacity of the board to hold a screw. This test was done by fastening two screws from the surface on both sides until it reached the bottom of the board and then subjected to a pulling force from the UTM. The screws were drawn vertically from the sample.

Table 2. Percentage of binding agent per type of board.

\begin{tabular}{l|cc}
\hline Agricultural waste & Binding agent & Percentage (By desired density) \\
\hline Corn husk & Waste plastics & $60 \%$ Plastics \\
Peanut shell & UF & $12 \%$ resin content \\
Banana sheath & UF & $47 \%$ UF \\
\hline
\end{tabular}


The UTM showed the force required to do that. The purpose of using the screw was for its mechanical ability, the ability to pass through a surface just by turning it, making it much better to use than a nail.

The FSHT was determined using the formula:

$$
\operatorname{FSHT}(\mathrm{kg})=\frac{P_{1}+P_{2}}{2}
$$

where:

$P_{1}=$ Load on one side $(\mathrm{kg}) ; P_{2}=$ Load on the opposite side $(\mathrm{kg})$.

Thickness swelling (TS) and water absorption (WA). TS and WA measure the amount of water absorbed by the boards after 24 hours of soaking. The weight and thickness of each specimen were measured before submerging them in water. After soaking, the specimens were then measured again to determine the amount of water absorbed.

TS was determined using the formula:

$$
\operatorname{TS}(\%)=\frac{T_{f}-T_{i}}{T_{i}} \times 100
$$

where,

$T_{f}=$ Final thickness; $T_{i}=$ Initial thickness.

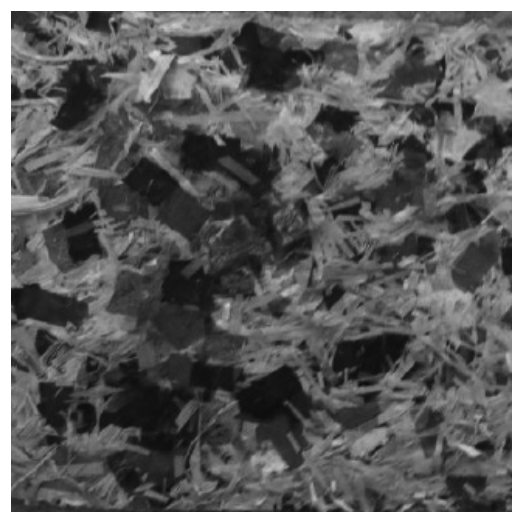

WA was determined using the formula:

$$
\mathrm{WA}(\%)=\frac{W_{f}-W_{i}}{W_{i}} \times 100
$$

where

$W_{f}=$ Final weight; $W_{i}=$ Initial weight.

For the comparison of the parameters MOR, IB, FSHT/NPHT, thickness swelling and water absorption; the statistical tool used was one tailed $t$-test, considering average value equivalence or non-equivalence to standard value, upper and lower bound tailed $t$-test were considered depending on the value of the PNS.

\section{RESULTS AND DISCUSSION}

The observed physical properties of the three different boards did not vary significantly. Both the banana sheath and corn husks boards had smooth surfaces while the peanut shell board was slightly rough; all boards reveal the colour of the materials used and were compact with plane surfaces.

For the banana sheath and peanut shell boards, the colour of the raw materials were evident since the binding agent used was colourless. The differing colours of the plastic strips in the cornhusk board dominate although the husk strips are also observed.

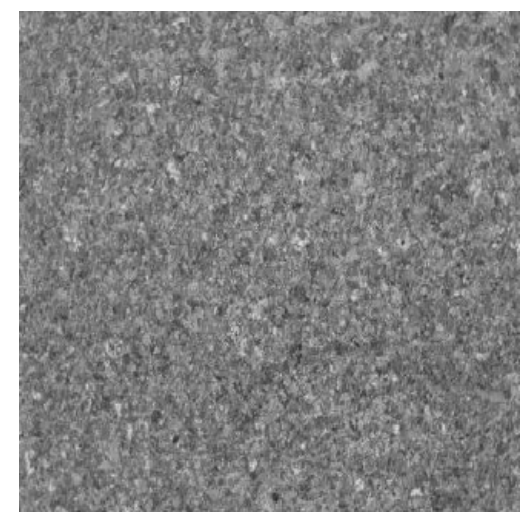

Figure 6. Samples of the composite boards: (Left) corn husks board, and (Right) peanut shells board. 
The mechanical properties of the boards are shown in Table 3 indicating the values obtained from the tests as compared with the PNS specifications for Type 100 particle board and the statistical comparison in graphical form can be seen in Figures.

\section{Banana Sheath Fibreboard}

For the average density of $0.6451 \mathrm{~g} / \mathrm{cc}$, a 0 $p$-value for the upper bound tailed $t$-test was obtained indicating the probability of achieving a value greater than $0.4 \mathrm{~g} / \mathrm{cc}$ and a $p$-value of 1.000 for the upper bound tailed $t$-test was obtained indicating a value not greater than $0.8 \mathrm{~g} / \mathrm{cc}$. The statistical results for the density indicated conformance to the PNS in terms of density. The banana sheath board after being soaked in water for 24 hours, obtained an average of $44.66 \%$ water absorption which was greater than the maximum amount set by the PNS as depicted on the $p$-value of 0.016 for the upper bound tailed $t$-test, an indication of non-conformance to PNS. A consistent average value of $14.29 \%$ thickness swelling was obtained, which was below $20 \%$, the maximum set by the PNS for Type 100 . In terms of strength, the board resisted an average $55.33 \mathrm{~kg}$ of load in the NHPT having a $p$-value of 0.022 for the upper bound tailed $t$-test indicating a non-probable equivalence to $30 \mathrm{~kg}$ and greater than $30 \mathrm{~kg}$, and a $p$-value of 0.216 for upper bound tailed $t$-test indicating probable non-equivalence to $50 \mathrm{~kg}$ and not greater than $50 \mathrm{~kg}$. In general, the NHPT for the banana sheath fibreboard conformed to the PNS. The MOR obtained an average value of $213.6 \mathrm{~kg} / \mathrm{cm}^{2}$, which conformed to the PNS (minimum of $80 \mathrm{~kg} / \mathrm{cm}^{2}$ ) as reflected by 0.019 of $p$-value for upper bound tailed $t$-test. However, in the IB test, the banana sheath fibreboard obtained $1.0367 \mathrm{~kg} / \mathrm{cm}^{2}$ less than to the standard minimum value of $2 \mathrm{~kg} / \mathrm{cm}^{2}$. Based on the statistical results, a probable non-equivalence to $2 \mathrm{~kg} / \mathrm{cm}^{2}$ or not greater than the said value was concluded as depicted by the $p$-value of 0.996 upper bound tailed $t$-test indicated a non-conformance to PNS.

Table 3. The physical properties of the composite boards.

\begin{tabular}{l|lccc}
\hline Physical properties & Banana sheath & Peanut board & Corn husk & PNS \\
\hline Surface texture & Smooth & Slightly rough & Smooth \\
Material integrity & $\begin{array}{c}\text { Compact with } \\
\text { plane surface }\end{array}$ & $\begin{array}{c}\text { Compact with } \\
\text { plane surface }\end{array}$ & $\begin{array}{c}\text { Compact with plane } \\
\text { surface }\end{array}$ & - \\
& Light brown & Light brown & $\begin{array}{c}\text { Multicoloured due to } \\
\text { plastic used }\end{array}$ & - \\
& & & $40 \%$ corn $/ 60 \%$ & \\
Colour & & plastic husk by & - \\
Proportion & $57 / 43$ UF & content & weight & \\
& & &
\end{tabular}

Table 4. The mechanical properties of the composite boards.

\begin{tabular}{l|cccc}
\hline \multicolumn{1}{c|}{ Mechanical properties } & Banana sheath & Peanut board & Corn husk & Standard for type 100 \\
\hline Density (g/cc) & 0.6451 & 0.6565 & 0.6867 & $0.4-0.8$ \\
Water absorption (\%) & 44.66 & 72.05 & 29.29 & $30(\max )$ \\
Thickness swelling (\%) & 14.29 & 13.474 & 5.597 & $20(\mathrm{max})$ \\
NHPT/ FSHT $(\mathrm{kg})$ & 55.33 & 30.83 & 26.33 & $30(\mathrm{~min})$ \\
Internal bond $\left(\mathrm{kg} / \mathrm{cm}^{2}\right)$ & 1.0367 & 2.396 & 2.22 & $2(\mathrm{~min})$ \\
Modulus of rupture $\left(\mathrm{kg} / \mathrm{cm}^{2}\right)$ & 213.6 & 46.57 & 162.1 & $80(\mathrm{~min})$ \\
\hline
\end{tabular}




\section{Peanut Shell Fibreboard}

The average density of the peanut shell board samples that were subjected to the different tests was $0.0 .6565 \mathrm{~g} / \mathrm{cc}$ with a $p$-value of 0 for the upper bound tailed $t$-test for the lower standard value of $0.4 \mathrm{~g} / \mathrm{cc}$ and $p$-value of 0 for the lower bound tailed $t$-test. The statistical results indicates the probability of the average density within the PNS $0.4-0.8 \mathrm{~g} / \mathrm{cc}$. The average water absorption obtained was $72.05 \%$ with a $p$-value of 0.002 for the upper bound tailed $t$-test indicating a probability of the value greater than $30 \%$, an indication of non-conformance to PNS. The thickness swelling obtained was
$13.474 \%$ with a $p$-value of 0.011 for the lower bound tailed $t$-test. The thickness swelling for the peanut shell fibreboard conformed to PNS. The WA of the board was quite high as compared to the standard maximum value of $30 \%$; in contrast with the TS result where the maximum value was $20 \%$. Meanwhile, the NHPT/FSHT, IB and MOR results obtained $30.83 \mathrm{~kg}, 2.396 \mathrm{~kg} / \mathrm{cm}^{2}$, and $46.57 \mathrm{~kg} / \mathrm{cm}^{2}$, respectively. The statistical results for the NHPT indicates a $p$-value of 0.444 for the upper bound tailed $t$-test in comparison with the lower limit standard and a $p$-value of 0.033 for the lower bound tailed $t$-test in comparison

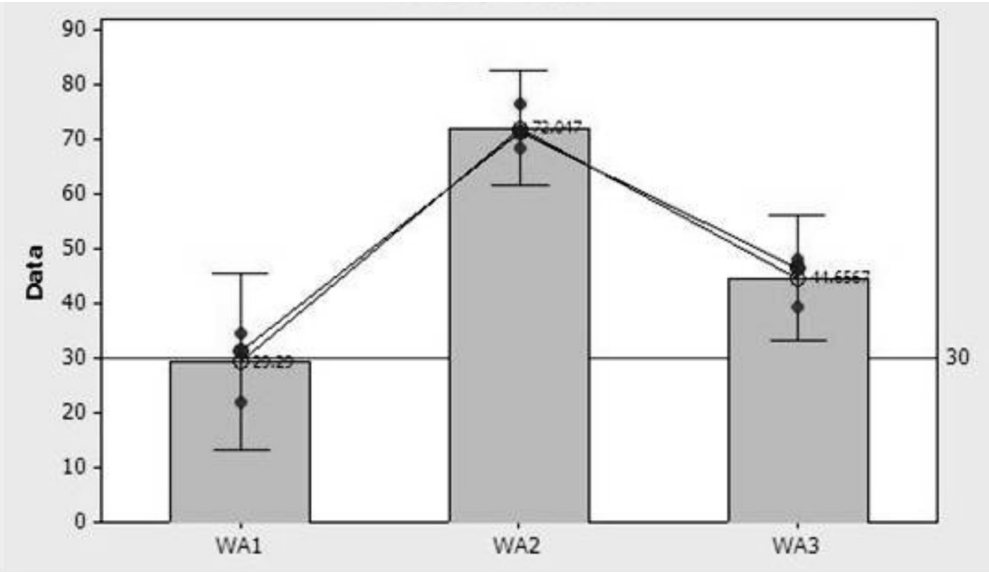

Figure 7. Statistical confidence interval for water absorption (\%).

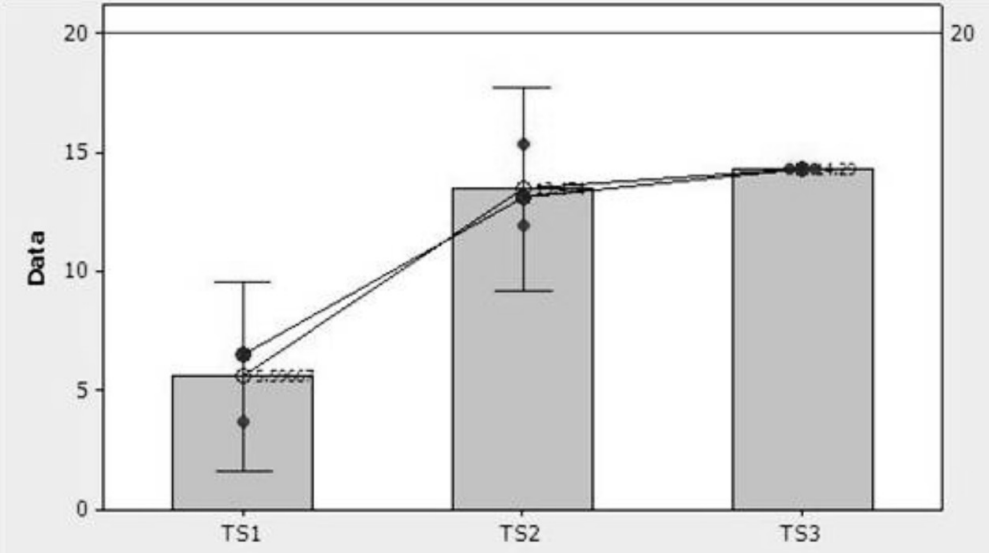

Figure 8. Statistical confidence interval for thickness swelling results (\%).

\section{Nomenclature:}

Subscripts

1 - Corn husk - Plastic composite boards

2 - Peanut shell Resin composite boards

3 - Banana - UF composite boards

WA - water absorption (\%)

TS - thickness swelling (\%)

D - density (g/cc)

IBS - Internal bond strength $\left(\mathrm{kg} / \mathrm{cm}^{2}\right)$

MOR - Modulus of rapture $\left(\mathrm{kg} / \mathrm{cm}^{2}\right)$

FSH - Face Screw Head Test or Nail Head Pull Through (kg) 
with the upper limit standard. The IB statistical evaluation obtained a $p$-value of 0.305 to check for equivalence of the average value to that of the minimum value of the standard. This indicated a probable equivalence to $2 \mathrm{~kg} /$ $\mathrm{cm}^{2}$. The MOR indicates a p-value of 0.004 for the lower bound tailed $t$-test indicated a probability of lesser value with the standard or non conformance to PNS for type 100 boards.

\section{Corn Husks Fibreboard}

The corn husks board samples tested had an average density of $0.6867 \mathrm{~g} / \mathrm{cc}$ with a $p$-value of 0 for the upper bound tailed $t$-test for the comparison with the lower limit standard and a $p$-value of 0 for the lower bound tailed $t$-test for the comparison with the upper limit standard. The density of the corn husks board conformed to the PNS. As for the WA, an average value

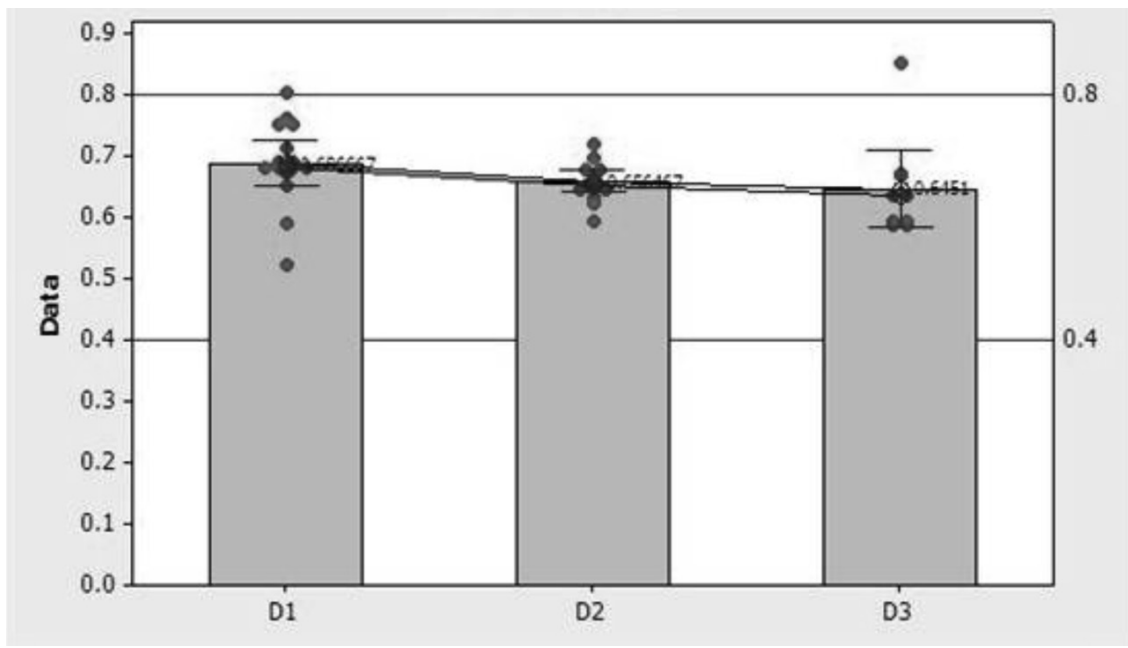

Figure 9. Statistical confidence interval for density $(\mathrm{g} / \mathrm{cc})$.

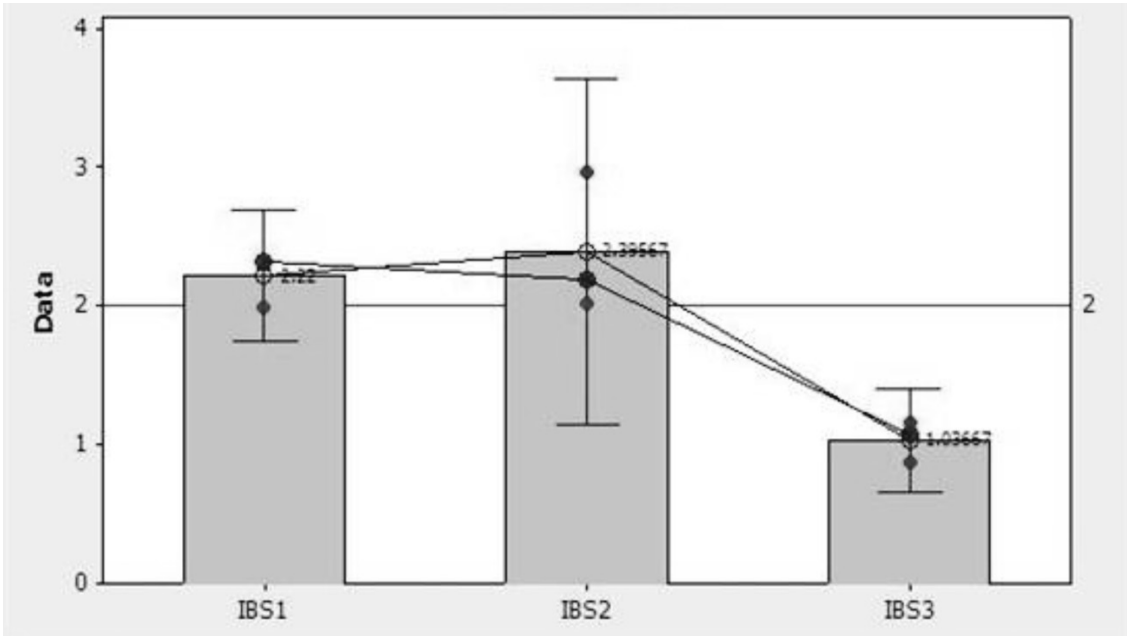

Figure 10. Statistical confidence interval for internal bond strength $\left(\mathrm{kg} / \mathrm{cm}^{2}\right)$. 


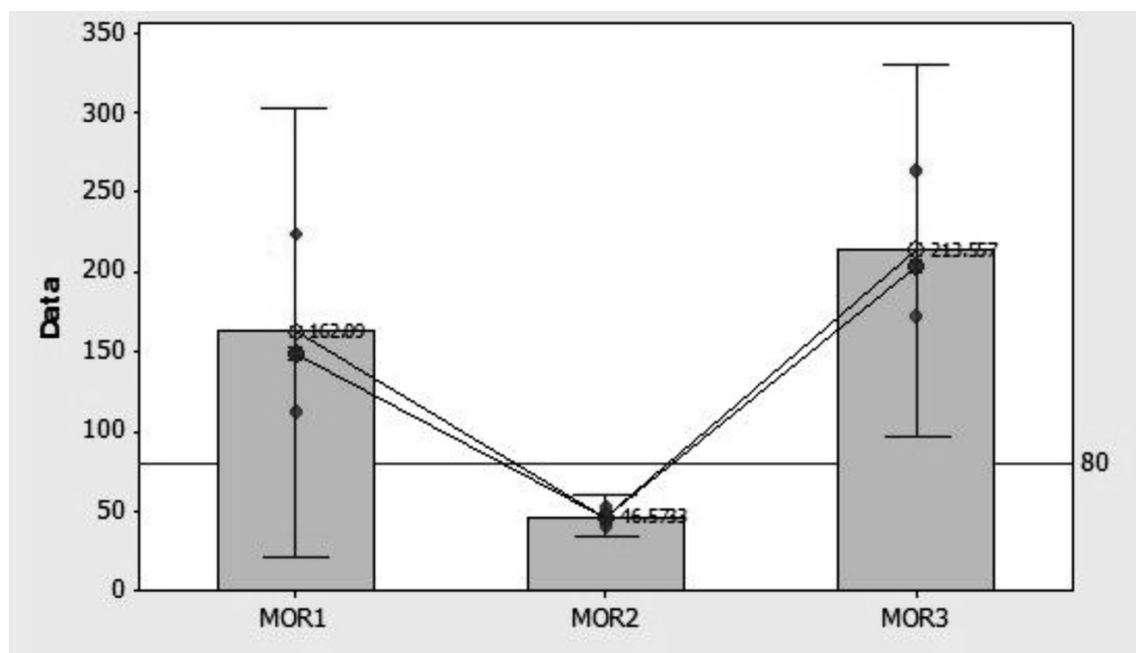

Figure 11. Statistical confidence interval for modulus of rupture $\left(\mathrm{kg} / \mathrm{cm}^{2}\right)$.

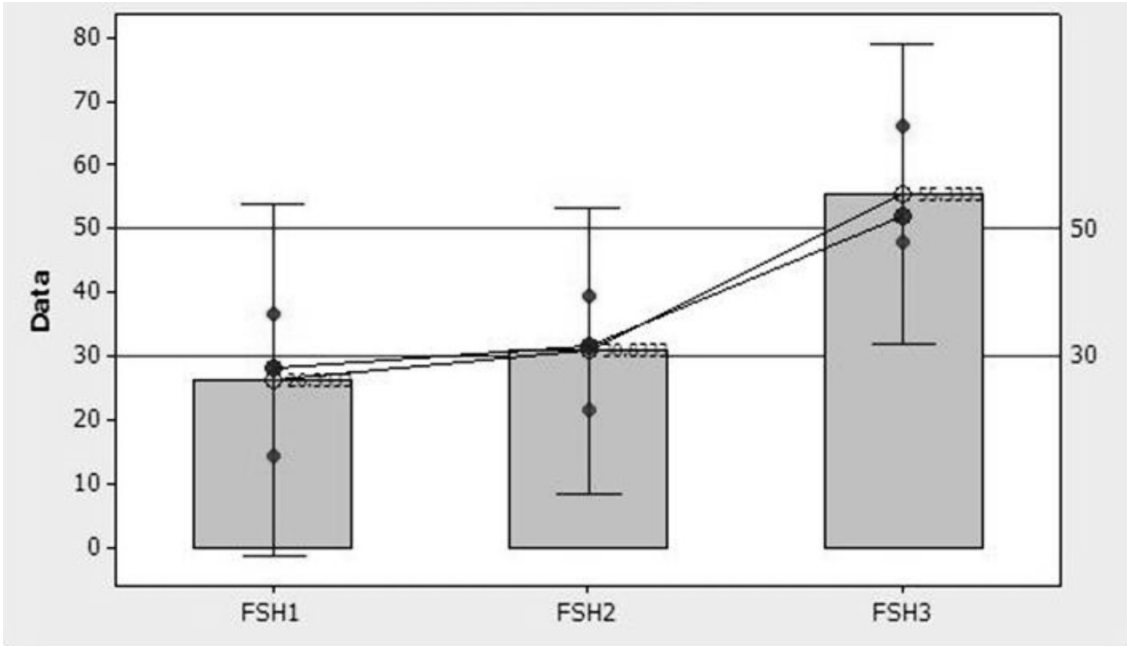

Figure 12. Statistical confidence interval for face screw head test or nail head pull through (kg).

of $29.29 \%$ was obtained with a $p$-value of 0.868 based on the statistical comparison being equivalent or not equivalent to the standard indicated probable equivalent to $30 \%$ maximum value, conforming to the PNS. On the case of thickness swelling, an average value of $5.597 \%$ was obtained with a $p$-value of 0.002 for the lower bound tailed $t$-test by comparison with the maximum value of $20 \%$. FSHT/NHPT was $26.33 \mathrm{~kg}$, IB was $2.22 \mathrm{~kg} / \mathrm{cm}^{2}$, and the MOR was $162.1 \mathrm{~kg} / \mathrm{cm}^{2}$. A $p$-value of 0.312 was obtained for FSHT/NHPT for the one tailed $t$-test for the evaluation of the equivalence of the average value with that of the lower limit standard, 0.184 was obtained for IB for the one tailed $t$-test for the evaluation of the equivalence 
of the average value with that of the minimum standard, and 0.129 for MOR for the one tailed $t$-test for the evaluation of the equivalence of the average value with that of the minimum standard.

The banana sheath board was very strong against rupture followed by the cornhusk board while the peanut board passed the standard value for the test with only a slight margin. However, with respect to internal bond, the peanut shell board is stronger than the other two. The banana sheath and peanut shell boards had almost the same resistance against nail head and face screw pull through. The corn husks board, when soaked in water did not swell as much as the other two boards, its water absorption falling within the range for Type 100. Only the corn husk-plastic composite boards conformed to standards for all parameters. The peanut shellresin composite boards conformed in density, thickness swelling, IB, and NHPT/FSHT; while, the banana sheath-UF composite boards conformed in thickness swelling, density, MOR and NHPT/FSHT.

\section{CONCLUSIONS}

Based on the results of the tests conducted, the following conclusions were drawn:

1. Agricultural wastes such as banana sheath, peanut shells and corn husks could be used as alternative materials in the production of particleboard.

2. The boards produced from these materials could be used as Type 100 particleboard.

3. The boards' relatively high water absorption could limit their use to dry condition applications such as shelves, cabinets, partition walls or office tabletops and the like. However, the tested boards were bare in contrast to the commercially-used boards which were already laminated when put into service.

\section{RECOMMENDATIONS}

From the stated conclusions, the researchers proposed the following recommendations:

1. Commercial production of any or all of these boards could be pursued in conjunction with other government thrusts or programme such as waste minimization.

2. Appropriate binder in line with the objectives of using agricultural waste for material production could be considered for the commercial production of the boards: face screw holding capacity for corn husk board could also be enhanced by better binder.

3. Production process could be standardized to address the strength-deficiencies of the boards. Reducing the individual fibre length of the banana sheath could also increase the internal bond strength of banana sheath board.

4. Pursuing the commercial feasibility or production of the boards could be turned over by Batangas State University to the industry in order to effect the benefits possible from the use of the subject agricultural wastes.

Date of submission: October 2012

Date of acceptance: February 2013

\section{REFERENCES}

Baconguis, SR 2008, 'Charcoal briquettes: fueling viable micro-financed and community-based livelihood enterprise', 4th National Biotechnology Week Institute of Small-Scale Industries (ISSI), University of the Philippines, Diliman, Quezon City, Philippines, viewed September 2009, $<$ http://emb.gov.ph/nswmc/alt/bio/Charcoal $\% 20$ Briquettes.PDF $>$.

Bieak, N \& George, BR 2003, Utilization of peanut shell fibres in non-woven erosion control materials, $<\mathrm{http}: / /$ www.inda.org/subscrip/inj03_4/ p60-65-george.pdf $>$. 
Childs, E \& Abajian, A 2006, 'Physico-chemical characterization of peanut hull as a potential fibre additive, Journal of Food Science, vol. 41, no. 5, pp. 1235-1236.

"Hulls" AgTech 2002, <http://www.goldenpeanut. com/hulls.htm>.

Macatangay, PM 2010, 'Sugar cane bagasse as an alternative raw material in the production of fibre-cement board', in Network of Calabarzon Educational Institutions Research Forum, Batangas City, Philippines.

Magundayao, EC, Mercado, LG \& Paral, CC 2006, 'Utilization of banana sheath as raw material in the production of fibreboard', undergraduate thesis, Batangas State University, Batangas City, Philippines.

Myers, DK 2009, 'Extension agronomist emeritus, forages, harvesting corn residue', viewed September 2009, <http://ohioline.osu.edu/agffact/0003.html $>$.

Pablo, AA, Ella, AB, Perez, EB, Casal, EU 1975, 'Manufacture of particleboard using mixtures of banana stalk (saba, musa, compress blanco) and kaatoan bangkal (Athocephalos chinenses (Rich) Ex.Walp.) wood particles', Forpride Digest, vol. 4, pp. 36-44.
Palomar, MK 1998, 'Peanut in the Philippine food system: a macro study, <http://www.lanra.uga. edu/peanut/download/report1.pdf $>$.

Philippine Agriculture Stats, (nd), 'Usage implies agreement with terms', <http://www. nationmaster.com/red/country/rp-philippines/ agr-agriculture\&b_cite $=1>$.

Reddya, N \& Yang, Y 2005, 'Properties and potential applications of natural cellulose fibres from cornhusks', 'Green chem.', Royal Society of Chemistry vol. 7, pp. 190-195, $<$ http://www.rsc.org/delivery/_ArticleLinking/ DisplayArticleForFree.cfm?doi=b415102j\&Jou rnalCode $=\mathrm{GC}>$.

Rivera, RA (2004), 'Banana production and marketing', <http://hvcc.da.gov.ph/pdf/banana phil_prodn_market.pdf>.

Rowell, RM 1996, 'Paper and composites from agrobased resources', eds RM Rowell, RA Young, \& Rowell, J, in Properties of composite panels, JA Youngquist et al., Chap 9, CRC Press.

University of Minnesota (nd), 'Lesson 1: tree growth and wood material at university of minnesota extension, $<\mathrm{http}$ ://en.wikipedia.org/ wiki/Wood\#cite_note-3>. 